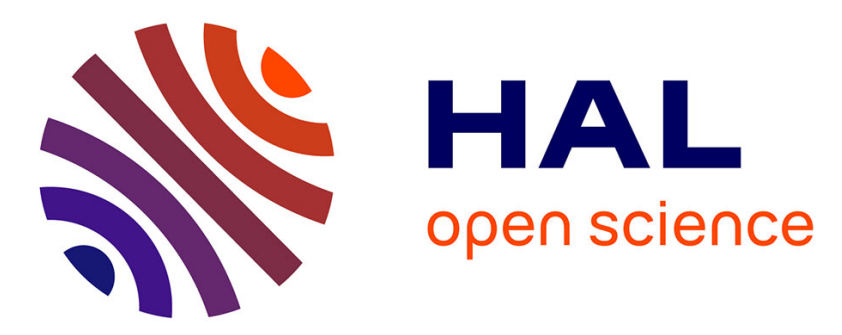

\title{
Absence of positive effect of black cohosh (Cimicifuga racemosa) on fracture healing in osteopenic rodent model
}

Leila Kolios, Florian Daub, Stephan Sehmisch, Karl Heinz Frosch, Mohammed Tezval, Klaus Michael Stuermer, Wolfgang Wuttke, Ewa Klara Stuermer

\section{To cite this version:}

Leila Kolios, Florian Daub, Stephan Sehmisch, Karl Heinz Frosch, Mohammed Tezval, et al.. Absence of positive effect of black cohosh (Cimicifuga racemosa) on fracture healing in osteopenic rodent model. Phytotherapy Research, 2010, 24 (12), pp.1796. 10.1002/ptr.3176 . hal-00552429

\section{HAL Id: hal-00552429 https://hal.science/hal-00552429}

Submitted on 6 Jan 2011

HAL is a multi-disciplinary open access archive for the deposit and dissemination of scientific research documents, whether they are published or not. The documents may come from teaching and research institutions in France or abroad, or from public or private research centers.
L'archive ouverte pluridisciplinaire HAL, est destinée au dépôt et à la diffusion de documents scientifiques de niveau recherche, publiés ou non, émanant des établissements d'enseignement et de recherche français ou étrangers, des laboratoires publics ou privés. 


\section{Absence of positive effect of black cohosh (Cimicifuga racemosa) on fracture healing in osteopenic rodent model}

\begin{tabular}{|r|l|}
\hline Journal: & Phytotherapy Research \\
\hline Manuscript ID: & PTR-09-0950.R2 \\
\hline Diley - Manuscript type: & Full Paper \\
\hline Author: & 02-Mar-2010 \\
\hline Complete List of Authors: & $\begin{array}{l}\text { Kolios, Leila; University of Goettingen, Department of Trauma and } \\
\text { Reconstructive Surgery } \\
\text { Daub, Florian; University of Goettingen, Department of Trauma and } \\
\text { Reconstructive Surgery } \\
\text { Sehmisch, Stephan; University of Goettingen, Department of } \\
\text { Trauma and Reconstructive Surgery } \\
\text { Frosch, Karl; University of Goettingen, Department of Trauma and } \\
\text { Reconstructive Surgery } \\
\text { Tezval, Mohammed; University of Goettingen, Department of } \\
\text { Trauma and Reconstructive Surgery } \\
\text { Stuermer, Klaus; University of Goettingen, Department of Trauma } \\
\text { and Reconstructive Surgery } \\
\text { Wuttke, Wolfgang; University of Goettingen, Department of Clinical } \\
\text { and Experimental Endocrinology } \\
\text { Stuermer, Ewa; University of Goettingen, Department of Trauma } \\
\text { and Reconstructive Surgery }\end{array}$ \\
\hline \hline Keyword: & $\begin{array}{l}\text { fracture healing, Cimicifuga racemosa , osteoporosis, estrogen, } \\
\text { phytohormones }\end{array}$ \\
\hline \hline
\end{tabular}

\section{5 scholarONE \\ Manuscript Central}




\title{
Absence of positive effect of black cohosh (Cimicifuga racemosa) on fracture healing in osteopenic rodent model \\ Leila Kolios ${ }^{1}$, Florian Daub 1, Stephan Sehmisch 1, Karl-Heinz Frosch', Mohammed Tezval ${ }^{1}$, Klaus Michael Stuermer ${ }^{1}$, Wolfgang Wuttke ${ }^{2}$, Ewa Klara Stuermer ${ }^{1}$
}

\begin{abstract}
Affiliation
1Department of Trauma and Reconstructive Surgery, Georg-August-University of Goettingen

${ }^{2}$ Department of Clinical and Experimental Endocrinology, Georg-August-University of Goettingen
\end{abstract}

\section{Corresponding author}

Leila Kolios, M.D.

Department of Trauma, Plastic- and Reconstructive Surgery

Georg-August-University of Goettingen

Robert-Koch-Str. 40

D-37075 Goettingen

Germany

Phone: 0049-551-39-22642

Fax: 0049-551-39-8991

Email: leilakolios@freenet.de

This work was supported by the DFG (STU 478/2-1). 


\begin{abstract}
Healing of predominantly metaphyseal fractures in postmenopausal osteoporosis is delayed and comparatively poor. Due to potential side effects of HRT, natural alternatives are appealing. The aim of this study was to determine whether Cimicifuga racemosa extract BNO 1055 improves metaphyseal fracture healing in severe osteopenic bone in rats.
\end{abstract}

Thirty-three twelve-week-old female rats developed severe osteopenia during ten weeks after ovariectomy. After metaphyseal tibial-osteotomy and standardized Tplate-osteosynthesis healing-period in ovariectomized rats $(C), 17-\beta$-estradiol-(E) and Cimicifuga racemosa-(CR) supplemented diets were assessed for 35 days. Changes in callus-morphology were evaluated qualitatively by biomechanical testing and quantitatively in microradiographies and fluorochrome-labeled histological sections.

CR-supplementation slightly improved callus quality and trabecular bone-formation. It significantly enhanced endosteal callus density (Cl.Dn.e C:59.08 \pm 21.89 , $\left.\mathrm{E}: 45.95 \pm 18.39, \mathrm{CR}: 60.85^{\perp} \pm 18.66\right)$, though most of the other morphological parameters examined showed no improvement. Time-course of fracture healing did not change due to $\mathrm{CR}$. Estrogen-supplementation enhanced biomechanical properties of fracture-site. Trabecular bone was improved indicating the physiological endosteal healing process.

CR-supplementation did not exhibit positive effects in severe (senile) osteopenic fracture healing as seen in early (postmenopausal) osteoporosis in rats. Callusformation was slightly improved under CR. Estrogen improved fracture healing in severe osteopenic bone, while the extent of callus formation played a minor role. 


\begin{abstract}
Keywords fracture healing - Cimicifuga racemosa - osteoporosis - estrogen phytohormones
\end{abstract}

Introduction

Osteoporosis has become one of the most prominent health problems due to increased life expectancies and changing population demographics. It is often recognized when the fracture occurs (Eisman et al., 2004), while most patients are not examined (Häussler et al., 2007) and not treated in accordance with the evidence-based clinical guidelines for osteoporosis (Feldstein et al., 2003). In the context of the hormonal changes that occur after menopause, bone turnover increases and an imbalance between bone formation and bone resorption develops (Savoca et al., 2007). Bone mineral density (BMD) is decreased, bone microarchitecture is disrupted, and the amount and variety of non-collagenous proteins in bone are altered (Boonen et al., 2008). These changes occur primarily in the trabecular bone of the metaphyses, resulting in increased fragility (Curtis et al., 2005). Fracture healing process in osteoporotic bone is delayed and qualitatively reduced (McCann et al., 2008; Hao et al., 2007). Bone-improving substances administered at the time of internal fixation could substantially alleviate this problem (Stuermer et al., 2008; Kolios et al., 2009 (1).

Black cohosh (Cimicifuga racemosa (CR)) exerted estrogenic effects in the bone tissue (Seidlova-Wuttke et al., 2003, 2009; Viereck et al., 2005) via an estrogen 
receptor-dependent mechanism (Chan et al., 2008). Extracted from the rhizomes of Cimicifuga racemosa (black cohosh), this substance enhances differentiation and increases the OPG-to-RANKL (regulators of bone metabolism) ratio of normal human osteoblasts, contributing to the positive skeletal effects of CR (Viereck et al., 2005). Extracts have also been proven to reduce climacteric complaints as efficiently as conjugated estrogens without exerting estrogenic effects in the uterus (SeidlovaWuttke et al., 2009). The effect of CR on osteoporotic fracture healing remains unclear.

Application of HRT for postmenopausal bone changes is continually discussed. Estrogen (17ßE) has shown potential to protect against coronary-artery disease (Hsia et al., 2006), diabetes mellitus (Salpeter et al., 2006) and Alzheimer's disease (Zandi et al., 2002). However, after long-term administration, HRT increased the incidence of breast cancers, thromboembolic events, stroke, and cardiovascular disease (Roussouw et al., 2002; Horwitz et al., 2008; Beral et al., 2003). From the other hand, it exerted a protective effect on bone increasing BMD and decreasing fracture incidence (Tarakida et al., 2007; Gambacciani et al., 2007). According to the recent review of the WHI investigators (L'Hermite et al., 2008), HRT seems to be a valid option, especially in osteopenic women. During short-term fracture-healing period (4 to 10 weeks), the positive effects of estrogen administration may outweigh the negative effects observed during long-term treatment (Stuermer et al., 2008; Kolios et al., 2009(1, 2)). In recent treatment advances substances like bisphosphonates, calcitonin, SERMs (raloxifene) and strontium ranelate are recommended more than estrogen. In addition, next to calcium and vitamin D application, bone stimulating agents like parathyroid hormone or thiazide diuretics 
are applied for osteoporosis treatment (National Osteoporosis Foundation 2008, Theodorou et al. 2002).

In the present study, we examined the effects of Black cohosh extract BNO 1055 on metaphyseal fracture healing in ovariectomy-induced osteopenia in rats and compared its effect to that of $17-\beta$-estradiol administered at a physiological dosage. The animal model selected possessed severe untreated osteopenia, in which an occurring fracture was treated with Black cohosh or estrogen to improve bone healing.

\section{Materials and Methods}

\section{Animals and treatment groups}

Thirty-six three-month-old female Sprague-Dawley rats (Winkelmann, Borken, Germany) were ovariectomized under Xylazine (Rompun®, Bayer Health Care) and Ketamine (Ketanest $\mathrm{S} \AA$, Pfizer Pharma) (3.5 V/V, 1mL/kg) anesthesia. Within ten weeks on a diet of phytoestrogen-free food (ssniff SM R/M, $10 \mathrm{~mm}$ Pellets; ssniff Spezialitäten $\mathrm{GmbH}$, Soest, Germany), they developed severe osteopenia (bone loss about $40 \%$ BMD in the proximal tibia). After this period, all animals underwent a standardized metaphyseal tibia osteotomy and osteosynthesis with a five-hole Tshaped titanium plate (XS 57-05140, Stryker Trauma, Selzach, Switzerland), as previously described (Stuermer et al., 2008). Rats were housed 3-4 in standard cages under $12 \mathrm{~h}$ darkness : $12 \mathrm{~h}$ light regimes [fluorescent tubes (osram, Munich, Germany) with a color temperature of warm-white $(830=3000 \mathrm{~K})$ or neutral-white $\left(840=4000 \mathrm{~K} 9\right.$ ] at a constant temperature of $22 \pm 1^{\circ} \mathrm{C}$ and relative humidity of $55 \%$. 
The rats were divided in three groups containing 12 animals each. The first group, the osteopenic control group, received phytoestrogen-free pelleted food (C). The second group as fed with phytoestrogen-free food supplemented with 17- $\beta$-estradiol (E), $0.01 \mathrm{~g} / \mathrm{kg}$ rodent chow (Sigma Medical, Apeldoorn, Netherlands). The average daily intake was $0.097 \mathrm{~g}$. In the third group (CR), phytoestrogen-free food was supplemented with Cimicifuga racemosa which was an aqueous/ethanolic extract of the rhizomes of cultivated plants. The average intake was $24.9 \mathrm{mg} /$ day per rat. The preparation of the CR extract BNO1055 was as follows: ground CR rhizomes were maintained in 5 volumes of $50 \%$ ethanol for $48 \mathrm{~h}$ and, thereafter, were percolated with a speed of $500 \mathrm{~kg} / \mathrm{h}$. After filtration, the extract was concentrated under vacuum and dried up at 100-140 mbar according to the patent-protected process (Bionorica, Neumarkt, Germany). The product temperature did not exceed $40^{\circ} \mathrm{C}$ (SeidlovaWuttke et al., 2003(1)) (1.66 g/kg rodent chow, BNO 1055, Bionorica, Neumarkt, Germany). Phytoestrogen-free food contained 1000IE of vitamin D per kg chow, 1\% of calcium and $0,7 \%$ of phosphorus. The substances were administered at established oral doses (Stuermer et al., 2008; Seidlova-Wuttke et al., 2003) for a fracture-healing period of $35 \mathrm{~d}$ (Fig.1). All animals had free access to food and water throughout the experiment.

The animal study protocol was approved by the local regional government and conformed to German animal protection laws (District Government of Braunschweig, permission from 12/5/03, Az: 509.42502/01-53.03).

\section{Intravital fluorochrome labeling}

Deleted: ๆ

To visualize the location, the amount and the time-line of bone tissue deposition, fluorochrome stains (Merck, Darmstadt, Germany), which bind 
competitively to the calcium on the surface of hydroxylapatite in newly built bone, were injected subcutaneously (Rahn et al, 1976). The stains used included: xylenol (orange, $90 \mathrm{mg} / \mathrm{kg}$ ) on day 13 , calcein (green, $10 \mathrm{mg} / \mathrm{kg}$ ) on day 18, alizarin (red, 30 $\mathrm{mg} / \mathrm{kg}$ ) on days 24 and 26, and tetracycline (yellow, $25 \mathrm{mg} / \mathrm{kg}$ ) on day 35 (three hours before decapitation). The additional dose of alizarin red was administered on day 26 to intensify the color. With this labeling procedure, the chronological sequence of newly built bone, bone resorption and bone remodeling could be easily distinguished.

\section{Endpoint and specimen preparation}

The animals were decapitated while under deep $\mathrm{CO}_{2}$ anesthesia on day 35. This time point was chosen because callus formation is stable and peripheral resorption of the outer callus did not occur at this time. Tibiae were prepared; the skin, muscles and tendons of the lower leg were removed carefully. Exarticulation of the tibia-fibulan-complex and ankle joint followed; plate and screws were removed. Tibiae were immediately stored at $-80{ }^{\circ} \mathrm{C}$ until further analyses. The right and left tibiae were randomized and used for biomechanical testing, as well as histological and microradiographic analysis.

\section{$\underline{\text { Radiographic and biomechanical evaluation }}$}

Microfocus radiographs in the anterior-posterior and lateral views were taken, and fracture healing of each tibia was evaluated in a blinded manner. Particular attention was paid to the position of the implants, accidental fracturing of the fibula and axial deviation. Thereafter a previously described (Stürmer et al., 2006) standardized, three-point bending and breaking test device (ZWICK software, Bensheim, Germany) was used to examine the biomechanical properties of the callus area, including 
stiffness $(\mathrm{S})$ and yield load $(\mathrm{yL})$. The force $(\mathrm{N})$ was plotted against the distance of tibial bending $(\mathrm{mm})$. This curve shows a linear progression, with the first phase representing the stiffness of the bone. In the second part, the rise of the curve declines. Elasticity changes to irreversible plastic deformation. The onset of force declination and the force of first microfracturing, called yield load $(\mathrm{yL})$, were calculated.

\section{Morphologic evaluation}

Tibiae were defatted and embedded in methylmethacrylate. The central three $120 \mu \mathrm{m} \pm 10 \mu \mathrm{m}$ thick longitudinal sections were chosen for quantitative evaluation. Microradiographies were performed as previously described (Schenk et al., 1965). A light microscope (Leitz DM-RXE, Leica, Bensheim, Germany) with an I3 filter system (excitation filter $450-490 \mathrm{~nm}$, dichronic mirror $510 \mathrm{~nm}$, suppression filter $515 \mathrm{~nm}$ ) was used. The quantitative analysis of bone tissue was digitally determined by using the Quantimet digital image processing system (Leica DM-RXE, Bensheim, Germany). Thus, the same histological sections could be directly compared regarding microradiography and fluorescence-labeling.

\section{Evaluation and statistics}

X-rays were analyzed regarding the site and extension of callus formation, implant loosening and involvement of the fibula. Based on the bending graph, the stiffness and yield load were calculated. In the microradiographs, callus area density (amount of calcified tissue per $\mathrm{mm}^{2}$ /callus area) and width (mean width measured at 10 parallel lines perpendicularly to cortical bone) as well as cortical structure (density and width) and trabecular bone (three locations: ventro-medial, dorsal, endosteal) were determined digitally (Fig. 2g). Data are shown as the means of three 
microradiographic sections. For the intravital fluorochrome-labeled histological sections, the same areas were evaluated for the amount of bound calcein (green), alizarin (red) and tetracycline (yellow) labeling by using the Quantimet digital image processing system (Schenk et al., 1965) (Fig. 2a-f). The system was not able to detect xylenol (orange)-stained bone because only small islands of it surrounded by intensely green, calcein-labeled bone could be found. In addition, the total callus area was calculated [Abbreviations conform to ASBMR Nomenclature Committee (Parfitt et al., 1987)].

\section{Results}

\section{Body weight and food intake}

At the beginning of experiment, body weight of the animals did not differ significantly. After ovariectomy BW increased in all groups. BW in E group remained at the lowest level compared to the other treatment groups. BW in CR group was lower compared to that in $\mathrm{C}$ group at the end of the experiment, however, it was significantly higher than that observed in E group (Tab. 1). The daily food intake showed no significant differences between the groups throughout the experiment.

\section{$\underline{\text { Radiographic evaluation }}$}

The tibia osteotomies of all 36 rats healed adequately without implant loosening. In four rats (two each from the $\mathrm{C}$ and $\mathrm{E}$ groups), accidental fracturing of the fibula (probably during internal fixation) with axial deviation and visibly increased callus formation occurred. This biomechanical factor confounded the fracture-healing process, interfering with the given test substances; therefore, these tibiae were excluded from the study. 


\section{Biomechanical and microradiographic evaluation}

The stiffness was highest in the E-substituted group, followed by the CR group. This measure was slightly improved in comparison to osteopenic C (Stiffness [N/mm]: C:121.4 $\pm 47.08, E: 147.9 \pm 39.38, C R: 129.8 \pm 44.93)$. Stiffness showed the same distribution when related to body weight, but differences were more apparent (Stiffness BW-related [N/mm/g]: C:0.36 $\pm 0.13, E: 0.53 \pm 0.14, C R: 0.42 \pm 0.16$ ). Yield load was enhanced in the $E$ group, while $C R$ was on the level of $C$ group $C$ ( $y L[N]$ : C:76.41 $\pm 18.83, \mathrm{E}: 93.84 \pm 29.68, \mathrm{CR}: 76.21 \pm 14.91)$. The trend observed for body weight highlights the impact of the treatments: we observed significantly enhanced $y \mathrm{~L}$ in the $\mathrm{E}$ group and slightly enhanced $\mathrm{yL}$ in the $\mathrm{CR}$ group as compared to the $\mathrm{C}$ group

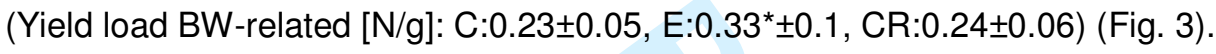

The ventromedial callus width was similar in E- and CR-substituted groups; both groups presented reductions in comparison to the $\mathrm{C}$ group. However, this trend was significant only for the CR group. Significantly more callus was built dorsally, as compared to the ventromedial region, in all three groups (Fig.4). Measurements of callus density, both ventromedially and dorsally, showed no differences between the groups. Endosteal callus density was significantly improved in CR group vs. E and was slightly superior to the levels observed in the $C$ group (Fig.5). The trabecular structure, in terms of trabecular width and density, number of nodes and nodular density was clearly improved under $\mathrm{E}$ treatment as compared to the $\mathrm{C}$ group (Fig.5, Tab.2). In the CR group, trabecular width and number of nodes were slightly improved compared to the $\mathrm{C}$ group. Otherwise, the trabecular area density was only 
slightly reduced in comparison to the osteopenic $\mathrm{C}$ group. None of the substances had any effect on the cortical structure (Fig.4, Tab.2).

\section{Evaluation of intravital fluorochrome labeling}

As measured in the fluorochrome-labeled sections, most callus apposition occurred in the endosteal region in all three groups (Fig. 6d), followed by the dorsal region. Regarding the time course of callus building in the osteopenic C group, a significant increase of callus apposition during the 35 days was visible in the ventromedial (Fig.6a) and endosteal (Fig.6c) regions. In the dorsal region (Fig.6b), levels of newly formed bone remained high throughout all three phases. In contrast, callus building in the E-supplemented group began with high values in the early CG-labeled period, surpassing those of the $\mathrm{C}$ group, especially ventromedially and endosteally. Callus building decreased during this period. Only in the ventromedial region did callus formation remain relatively constant (Fig.6a-C). In the CR group, the time course was similar to that observed in the $\mathrm{C}$ group, with only a slight increase in the amount of newly formed bone observed throughout the period studied (Fig.6a-c).

\section{Discussion}

Osteoporotic fractures affect the metaphyseal bone; in humans, these fractures occur mainly at the hip, the vertebrae, the proximal humerus and the wrist. Previous experimental studies on fracture healing in osteoporosis have, for the most part, examined the diaphyseal femur (Cao et al., 2002; Bolander et al., 1992) or tibia (Schmidmaier et al., 2001). Research on fracture healing in osteoporosis should be done predominantly at the metaphyseal bone, because osteoporosis affects the metaphyseal bone to the largest extent (Thompson et al., 1995; Wronski et al., 1985). Additionally, diaphyseal bone heals primarily with periosteal callus formation, 
while metaphyseal bone heals predominantly endosteally (Stuermer et al., 2008).

Therefore, a metaphyseal osteotomy model (Stuermer et al., 2008) was used. When osteotomy was performed, the bone structure was similar to that of typical elderly female patients, who are largely untreated for osteoporosis. This model should represent the severe, senile untreated osteoporosis, which is often seen in elderly patients who suffer from acute hip and spine fractures. Therefore, the Black cohosh and estrogen were used as immediate therapy after osteotomy (fracture) and not as a prophylaxis.

Herbal alternatives are popular due to the ongoing discussion about HRT and its adverse effects. Black cohosh as osteoporosis prophylaxis has shown bone protecting effects without estrogen-like effects on uterus in the mature osteopenic rat model (Seidlova-Wuttke et al., 2003, 2009; Viereck et al., 2005), with direct effects on the enhancement of bone nodule formation in osteoblasts. This action is mediated by an estrogen receptor-dependent mechanism (Chan et al., 2008). In a double-blind clinical trial with 62 postmenopausal women, researchers observed a bone-protecting effect of CR under low estrogen-like adverse conditions (Wuttke et al., 2003). In recent years, there have been several reports about hepatic events associated with the use of CR, such as acute hepatitis or hepatic failure (Huntley et al., 2003; Whiting et al., 2002; Levitsky et al., 2005). But new animal studies (Mazzanti et al., 2008) as well as prospective longitudinal clinical trials (Nasr et al., 2009) showed that CR did not affect liver morphology or hepatic function.

Previously, we have shown a positive effect of black cohosh on fracture healing processes (Kolios et al., 2009 (3)). It was given as a prophylaxis of osteoporosis in a ovariectomized rat. In the presented study, CR was tested regarding its anabolic 
effects at severely osteopenic bone. The biomechanical properties of fracture sites under CR therapy were slightly improved compared to the $\mathrm{C}$ group, although the difference was not significant and values did not reach those of the $E$ group. Regarding the morphological analysis, most of the calluses in the CR group were built in the endosteal region. Although the amount of endosteal callus was not enhanced in comparison to the $C$ and $E$ groups (Fig.6d), density was significantly improved under CR donation compared to the E group. The enhanced callus density contributes to the slightly improved biomechanical properties observed and the physiological healing process in the metaphysis. In addition, the trabecular structure (Fig.4b, c) was slightly but not significantly improved under CR donation. Regarding the time course of newly formed bone in the context of callus formation, CR does not ensure the potency of stabilizing fractures in the early healing period, as observed in the estrogen group. Compared to the osteopenic $\mathrm{C}$ group, the growth of callus tissue increased during the three periods examined in this study. Fracture healing is still in progress. Interestingly, dorsal area callus apposition decreases slightly in the second and third period as compared to the first CG labeled phase. The bridge plating with the induced, mainly dorsal-occurring micro-movements, in combination with CR therapy may lead to an earlier stabilization, so that in the later fracture healing period less new bone is necessary. In sum CR did not exhibit a positive effect on fracture healing, as was observed in early (postmenopausal) osteopenic bone. CR is able to preserve the bony structure and supports the fracture healing process in the bone matrix. However, CR did not exert sufficient anabolic effect to improve fracture healing in severe (senile) osteopenic bone. CR exhibited a slight but not significantly positive effect.

Concerning the mechanisms and the active principles of Cimicifuga racemosa in organisms, previously published data have been largely contradictory. Some authors 
suggest a direct interaction with estrogen receptors (Chan et al., 2008) or a several SERM activity of Black Cohosh contains (Seidlova-Wuttke et al., 2003). In contrast other reports negate any estrogen receptor activity of CR using several molecular biological assays (Lupu et al., 2003; Liu et al., 2001; Alves et al., 2008). Recent data have demonstrated that Black Cohosh may have an effect on dopaminergic and serotoninergic systems (Kanadys et al., 2008). Some evidence exists for the presence of monoaminergic substances in Cimicifuga racemosa extracts, which are important in bone homeostasis. Receptors for serotonin, noradrenaline and dopamine have been detected in osteoblasts and osteoclasts (Bouxsein et al., 2009; Elefterion, 2008; Graham et al., 2008; Haney et al., 2009; Warden and Haney, 2008). Serotonin and serotonin reuptake inhibitors have an osteoporosis-promoting effect on bone, conducted by osteoblasts. From the other hand, serotonin has an antiosteoporotic effect by inhibiting the sympathetic noradrenalin release via central nervous mechanisms. The latter may explain the mechanism of $C R$ action since the serotoninergic substances were detected in the CR extract (Burdette et al., 2003; Powell et al., 2008). Clinical study of Haney (2009) confirmed this coherence. Dopamine has anti-osteoporotic properties as shown in dopamine-transporter knockout mice, which had a more fragile bone than the wild-type ones (Bliziotes et al., 2000). The CR-extract BNO 1055 analyzed possessed dopaminergic mechanisms which have not been yet identified chemically (Jarry et al., 2003). The extract contains no estrogen-like substances, because the uterus weight and the estrogenregulated gene expression were not changed under BNO 1055 treatment (SeidlovaWuttke et al., 2003; Wuttke et al., 2003 (2)). In addition there are reports about other active principles of Black Cohosh as the biologically active constituents of triterpene glycoside and cycloartane glycoside (Gaube et al., 2007; Kanadys et al., 2008). These named neocimigenosides A and B 
were isolated and idendified by chromatographic and spectroscopic analyses by Mimaki et al., 2006. The triterpenoide are reported to exert inhibitory effect on osteoclastic bone resorption through the suppression of OCLs (osteoclast-like cells) formation and their resorbing activity and also showed a significant protective effect on BMD in OVX mice (Li et al., 2007). It is known that osteoclast activity is necessary and requested for fracture healing, because the damaged bone had to be metabolized and restructured. As it was observed for Genistein (Kolios et al., (1) 2009) osteoclast inhibition resulted in a less structured callus with poor biomechanical properties. CR seemed to have similar mode of action. Lie et al. (2007) showed a positive effect of CR as a prophylactic agent for osteoporosis. We confirmed the prophylactic effect of $\mathrm{CR}$ during fracture healing in the early stages of osteoporosis (Kolios et al., (3) 2009). However, CR given as a therapeutic agent has no potency to improve fracture healing in severe osteopenic bone.

Fractured callus treated with estrogen displays excellent biomechanical properties. Callus tissue becomes very elastic with significantly increased resistance to microfracturing. The reasons for this quality of the fracture site may be the enhanced amount of endosteal callus (Fig.6d), as well as the fortified trabecular structure (Fig.4b, c). Both are also signs of the physiological, endosteal fracture-healing process that are typical for the metaphysis. As typical for estrogen treatment, the ventromedial and dorsal callus levels were not enhanced in comparison to osteopenic bone; periosteal callus formation was reduced as compared to the endosteal callus. Endosteal healing is also typical for the metaphyseal healing of healthy bone. The results of the histological evaluation showed an increased amount of callus formation in the first CG-labeled period, especially in the ventromedial and endosteal regions of the $\mathrm{E}$ group as compared to the osteopenic $\mathrm{C}$ group. Callus 
formation decreased with time, which indicates that less bone is necessary during fracture healing to stabilize the osteotomy gap.

As previously described (Seidlova-Wuttke et al., 2003; Wronski et al., 1985), the influence of osteoporosis on the metaphyseal cortical bone is very low. In this study, CR and even estrogen did not change the cortical width or density. The influence on the diaphyseal bone may be completely different.

Although we focused in this study on bony structure and not on adverse effects of the substances, the systemic effect of substituted estrogen has to be mentioned. We observed that body weight in E group remained at the lowest level among the groups. CR showed less effect on body weight. As a mild systemic reaction, body weight was only slightly but not significantly lower compared to the osteoporotic $\mathrm{C}$ group after 5-week treatment.

The results of this study are presented while bearing in mind the methodological limitations of the work. The design of the study focused only on short-term application of the substances during the fracture-healing process. The healing and biomechanical properties might be different with long-term supplementation of estrogen and Cimicifuga racemosa. Aside from body weight, no systemic effects were analyzed in this study. With regard to the influence of estrogen and CR on the mammary glands and liver, it would be interesting to examine the possibility of structural changes due to short-term treatment. However, this study focused on osteopenic bone fracture healing, and we presume the possible effects of 5-week treatment would be slight and reversible. 


\begin{abstract}
Conclusions
Cimicifuga racemosa did not display any positive effect on fracture healing in severe (senile) osteopenic bone as in early (postmenopausal) osteoporosis in rats. Callus formation was only slightly improved under CR and healing of severe osteopenic bone was not accelerated. Estrogen as an anabolic agent was able to improve fracture healing in severe osteopenic bone as well. Its positive effects could outweigh possible adverse reactions of short-term treatment. Finally, the metaphyseal tibial osteotomy model in ovariectomized rats produced reliable results regarding the therapeutic effects of antiosteoporotic substances.
\end{abstract}

\title{
Acknowledgments
}

This work was supported by the DFG (STU 478/2-1). Thanks are due to Mrs. D. Seidlova-Wuttke for her support with ovariectomies and to Mr. F. Kauer, Mrs. A. Witt and Mrs. R. Castro for their assistance throughout the experiment. 


\section{References}

Alves DL, Lima SM, da Silva CR, Galvao MA, Shanaider A, de Almeida Prado RA, Aoki T. 2008. Effects of Trifolium pratense and Cimicifuga racemosa on the endometrium of Wistar rats. Maturitas 61: 364-370.

Beral V. 2003. Breast cancer and hormone-replacement therapy in the Million Women Study. Lancet 362: 419-427.

Bolander ME, Sabbagh R, Jeng C. 1992. Estrogen treatment during fracture repair strengthens healing callus in an osteoporotic model. Trans Orthop Res Soc 17:138.

Boonen S, Marin F, Obermayer-Pietsch B, Simoes ME, Barker C, Glass EV, Hadji P, Lyritis G, Oertel H, Nickelsen T, McCloskey EV; EUROFORS Investigators. 2008. Effects of previous antiresorptive therapy on the bone mineral density response to two years of teriparatide treatment in postmenopausal women with osteoporosis. $J$ Clin Endocrinol Metab 93: 852-60.

Bliziotes M, McLoughlin S, Gunness M, Fumagalli F, Jones SR, Caron MG. 2000. Bone histomorphometric and biomechanical abnormalities in mice homozygous for deletion of the dopamine transporter gene. Bone 26: 15-19.

Bouxsein ML, Devlin MJ, Glatt V, Dhillon H, Pierroz DD, Ferrari SL. 2009. Mice lacking beta-adrenergic receptors have increased bone mass but are not protected from deleterious skeletal effects of ovariectomy. Endocrinology 150: 144-152. 
Burdette JE, Liu J, Chen SN, Fabricant DS, Piersen CE, Barker EL, Pezzuto JM, Mesecar A, Van Breemen RB, Farnsworth NR, Bolton JL. 2003. Black cohosh acts as a mixed competitive ligand and partial agonist of the serotonin receptor. $J$ Agric Food Chem 51: 5661-5670.

Cao Y, Mori S, Mashiba T, Westmore MS, Ma L, Sato M, Akiyama T, Shi L, Komatsubara S, Miyamoto K, Norimatsu H. 2002. Raloxifene, Estrogen and Alendronate affect the processes of fracture repair differently in ovariectomized rats. J Bone Miner Res 17: 2237-2246.

Chan BY, Lau KS, Jiang B, Kennelly EJ, Kronenberg F, Kung AW. 2008. Ethanolic extract of Actaea racemosa (black cohosh) potentiates bone nodule formation in MC3T3-E1 preosteoblast cells. Bone 43: 567-573.

Curtis R, Goldhahn J, Schwyn R, Regazzoni P, Suhm N. 2005. Fixation principles in metaphyseal bone - a patent based review. Osteoporos Int 16: 54-64.

Eisman J, Clapham S, Kehoe L; Australian BoneCare Study. 2004. Osteoporosis prevalence and levels of treatment in primary care: the Australian BoneCare Study. $J$ Bone Miner Res 19: 1969-1975.

Elefterion F. 2008. Regulation of bone remodeling by central and peripheral nervous system. Arch Biochem Biophys 473: 231-236. 
Feldstein AC, Nichols GA, Elmer PJ, Smith DH, Aickin M, Herson M. 2003. Older women with fractures: patients falling through the cracks of guideline-recommended osteoporosis screening and treatment. J Bone Joint Surg Am 85: 2294-2302.

Gambacciani M, Pepe A, Cappagli B, Palmieri E, Genazzi AR. 2007. The relative contributions of menopause and aging to postmenopausal reduction in intervertebral disc height. Climacteric 10: 298-305.

Gaube F, Wolfl S, Pusch L, Kroll TC, Hamburger M. 2007. Gene expression profiling reveals effects of Cimicifuga racemosa (L.) NUTT. (black cohosh) on the estrogen receptor positive human breast cancer cell line MCF-7. BMC Pharmacol 20: 7-11.

Graham S, Hammond-Jones D, Gamie Z, Polyzois I, Tsiridis E. 2008. Expert Opin Investig Drugs 17: 1281-1299.

Haney EM, Warden SJ, Bliziotes MM. 2009. Effects of selective serotonin reuptake inhibitors on bone health in adults: Time for recommendations about screening, prevention and management? Bone [Epub ahead of print, Aug 5]

Hao YL, Zhang G, Wang YS, Qin L, Hung WY, Leung K, Pei FX. 2007. Changes of microstructure and mineralized tissue in the middle and late phase of osteoporotic fracture healing in rats. Bone 41: 631-638.

Häussler B, Gothe H, Göl D, Glaeske G, Pientka L, Felsenberg D. 2007. Epidemiology, treatment and costs of osteoporosis in Germany - the BoneEVA Study. Osteoporos Int 18: 77-84. 
Horwitz KB. 2008. The Year in Basic Science: update of estrogen plus progestin therapy for menopausal hormone replacement implicating stem cells in the increased breast cancer risk. Mol Endocrinol 22: 2743-2750.

Hsia J, Langer RD, Manson J. 2006. Conjugated equine estrogens and coronary heart disease: the Women's Health Initiative. Arch Intern Med 166: 357-365.

Huntley A, Ernst E .2003. A systematic review of the safety of black cohosh. Menopause 10:58-64.

Jarry H, Metten M, Spengler B, Christoffel V, Wuttke W. 2003. In vitro effects of the cimicifuga racemosa extract BNO 1055. Maturitas 44: 31-38.

Kanadys WM, Leszczynska-Gorzelak B, Oleszczuk J. 2008. Efficacy and safety of Black Cohosh (Actaea/Cimicifuga racemosa) in the treatment of vasomotor symptoms-review of clinical trials. Ginekol Pol 79: 287-296.

Kolios L, Hoerster AK, Sehmisch S, Malcherek MC, Rack T, Tezval M, SeidlovaWuttke D, Frosch KH, Stuermer KM, Stuermer EK. 2009. (1). Do Estrogen and Alendronate improve metaphyseal fracture healing when applied as osteoporosis prophylaxis? Calcif Tiss (Epub ahead of print , 2009 Dec 1).

Kolios L, Sehmisch S, Daub F, Rack T, Tezval M, Stuermer KM, Stuermer EK. 2009. (2). Equol but not genistein improves early metaphyseal fracture healing in osteoporotic rats. Planta Med 75: 459-465. 
Kolios L, Schumann J, Sehmisch S, Rack T, Tezval M, Seidlova-Wuttke D, Frosch

KH, Stuermer KM, Stuermer EK. 2009. (3). Effects of Black cohosh (Cimicifuga racemosa) and Estrogen on metaphyseal fracture healing in the early stage of osteoporosis in ovariectomized rats. Planta Med (accepted 16.12.2009).

L'Hermite M, Simoncini T, Fuller S, Genazzani AR. 2008. Could transdermal estradiol+progesterone be a safer postmenopausal HRT? A review. Maturitas 60:185-201.

Levitsky J, Alli TA, Wisecarver J, Sorrell MF. 2005. Fulminant liver failure associated with the use of black cohosh. Dig Dis Sci 50: 538-539.

Li Jx, Liu J, He CC, Yu ZY, Du Y, Kadota S, Seto H. 2007. Triterpenoids from Cimicifugae rhizoma, a novel class of inhibitors on bone resorption and ovariectomyinduced bone loss. 2007. Maturitas 58: 59-69.

Liu J, Burdette JE, Xu H, Gu C, van Breemen RB, Bhat KP, Booth N, Constantinou Al, Pezzuto JM, Fong HH, Farnsworth NR, Bolton JL. 2001. Evaluation of estrogenic activity of plant extracts for the potential treatment of menopausal symptoms. J Agric Food Chem 49: 2472-2479.

\begin{abstract}
Lupu R, Mehmi I, Atlas E, Tsai MS, Pisha E, Oketch-Rabah HA, Nuntanakorn P, Kenelly EJ, Kronenberg F. 2003. Black cohosh, a menopausal remedy, does not have estrogenic activity and does not promote breast cancer cell growth. Int J Oncol
\end{abstract} 23: $1407-1412$. 
Mazzanti G, Di Sotto A, Mastrangelo S, Pezzella M, Vitalone A, Mammola CL. 2008. Effects of Cimicifuga racemosa extract on liver morphology and hepatic function indices. Phytomedicine (epub ahead of print), PMID 18434119.

McCann RM, Colleary G, Geddis C, Clarke SA, Jordan GR, Dickson GR, Marsh D. 2008. Effect of osteoporosis on bone mineral density and fracture repair in a rat femoral fracture model. J Orthop Res 26: 384-393.

Mimaki Y, Nadaoka I, Yasue M, Ohtake Y, Ikeda M, Watanabe K, Sashida Y. 2006. Neocimicigenosides A and B, cycloartane glycosides from the rhizomes of Cimicifuga racemosa and their effects on CRF-stimulated ACTH secretion from AtT-20 cells. 2006. J Nat Prod 69: 829-832.

Nasr A, Nafeh H. 2009. Influence of black cohosh (Cimicifuga racemosa) use by postmenopausal women on total hepatic perfusion and liver functions. Fertil Steril (epub ahead of print). PMID 19539907.

National Osteoporosis Foundation (NOF). 2008. Clinician`s Guide to prevention and treatment of osteoporosis. National Osteoporosis Foundation, Washington, DC. Website: http://wwwnof.org/professionals/NOF_Clinicians:Guide.pdf

Parfitt AM, Drezner MK, Glorieux FH, Kanis JA, Malluche H, Meunier PJ, Ott SM, Recker RR. 1987. Bone Histomorphometry: Standardization of Nomenclature, Symbols, and Units. Report of the ASBMR Histomorphometry Nomenclature Committee. J Bone Miner Res 2: 595-610. 
Powell SL, Gödecke T, Nikolic D, Chen SN, Ahn S, Dietz B, Farnsworth NR, van Breemen RB, Lankin DC, Pauli GF, Bolton JL. 2008. In vitro serotoninergic activity of black cohosh and identification of $\mathrm{N}$ (omega)-methylserotonin as a potential active constituent. J Agric Food Chem 56: 11718-11726.

Rahn BA. 1976. The fluorochrome sequence labeling of the bone. Nova acta Leopold 44: $249-255$.

Roussouw JE, Anderson GL, Prentice RL, LaCroix AZ, Kooperberg C, Stefanick ML, Jackson RD, Beresford SA, Howard BV, Johnson KC, Kotchen JM, Ockene J. 2002. Risks and benefits of estrogen plus progestin in healthy postmenopausal women: principal results from the Women's Health Initiative randomized controlled trial. JAMA 288:321-333.

Salpeter SR, Walsh JME, Ormiston TM, Greyber E, Buckley NS, Salpeter EE. 2006. Meta-analysis: effect of hormone-replacement therapy on components of the metabolic syndrome in postmenopausal women. Diab Obes Metab 6: 538-554.

Savoca S, D'Agosta S, Lombardo G. 2007. Evaluation of the hematochemical parameters and bone mineral density of women in physiological menopause treated with hormone replacement therapy with nomegestrol acetate and surgical menopause treated with estrogen replacement. Part II. Minerva Ginecol 59: 215-222. Schenk RK. 1965. The histological preparation of undecalcified bone. Acta anat 60: 3-19. 
Schmidmaier G, Wildemann B, Bail H, Lucke M, Fuchs T, Stemberger A, Flyvberg A, Haas NP, Raschke M. 2001. Local application of growth factors insulin-like growth factor-1 and Transforming growth factor- $B$ from a biodegradable poly ( $D$, L-lactide) coating of osteosynthetic implants accelerated fracture healing in rats. Bone 28: 341 350.

Seidlova-Wuttke D, Hesse O, Jarry H, Christoffel V, Spengler B, Becker T, Wuttke W. 2003. Evidence for selective estrogen receptor modulator activity in a black cohosh (Cimifuga racemosa) extract: comparison with estradiol-17beta. Eur J Endocrinol 149: $351-62$.

Seidlova-Wuttke D, Jarry H, Becker T, Christoffel V, Wuttke W. 2003. Pharmacology of Cimicifuga racemosa extract BNO 1055 in rats: bone, fat and uterus. Maturitas 44: $39-50$.

Seidlova-Wuttke D, Jarry H, Wuttke W. 2009. Effects of Estradiol Benzoate, Raloxifen and an Ethanolic Extract of Cimicifuga racemosa in Nonclassical Estrogen Regulated Organs of Ovariectomized Rats. Planta Med Epub ahead of print; PMID 19350480.

Stuermer EK, Sehmisch S, Rack T, Wenda E, Seidlova-Wuttke D, Tezval M, Wuttke W, Frosch KH, Stuermer KM. 2008. Estrogen And Raloxifene Improve Metaphyseal Fracture Healing In The Early Phase Of Osteoporosis. A New Fracture-Healing Model at the Tibia In Rat. Lang Arch Surg. Published online December 02, 2008; PMID: 19048282. 
Stürmer EK, Seidlova-Wuttke D, Sehmisch S, Rack T, Wille J, Frosch KH, Wuttke W, Stürmer KM. 2006. Standardized bending and breaking test for the normal and osteoporotic metaphyseal tibias of the rat: effect of estradiol, testosterone, and raloxifene. J Bone Miner Res 21: 89-96.

Tarakida A, Higuchi T, Mizunuma H. 2007. Evidence of hormone replacement therapy for osteoporosis. Clin Calc 18: 1434-1441.

Theodorou DJ, Theodorou SJ.2002. Treatment of Osteoporosis: Current Status and Recent Advances. Comp Ther 28: 109-122.

Thompson DD, Simmons HA, Pirie CM, Ke HZ. 1995. FDA Guidelines and animal models for osteoporosis. Bone 17:125-133.

Viereck V, Gründker C, Friess SC, Frosch KH, Raddatz D, Schoppet M, Nisslein T, Emons G, Hofbauer LC. 2005. Isopropanolic extract of black cohosh stimulates osteoprotegerin production by human osteoblasts. J Bone Miner Res 20:2036-2043.

Warden SJ, Haney EM. 2008. Skeletal effects of serotonin (5-hydroxytryptamine) transporter inhibition: evidence from in vitro and animal-based studies. $J$ Musculoskelet Neuronal Interact 8:121-132.

Whiting PW, Clouston A, Kerlin P. 2002. Black cohosh and other herbal remedies associated with acute hepatitis. Med J Aust 177: 440-443. 
Wronski TJ, Lowry PL, Walsh CC, Ignaszewski LA. 1985. Skeletal alterations in ovariectomized rats. Calcif Tiss Int 37: 324-328.

Wuttke W, Seidlova-Wuttke D, Gorkow C. 2003. The Cimicifuga preparation BNO 1055 vs. conjugated estrogens in a double-blind placebo-controlled study: effects on menopause symptoms and bone markers. Maturitas 44: 67-77.

Wuttke W, Jarry H, Becker T, Schultens A, Christoffel V, Gerkow C, Seidlova-Wuttke D. 2003 (2). Phytoestrogen: endocrine disrupters or replacement for hormone replacement therapy? Maturitas 44: 9-20. 


\section{Figure legends}

Tab. 1: Changes in bodyweight determined at ovariectomy, osteotomy and obduction. Daily food intake and daily intake of pure $17 \beta$ estradiol (group E), or BNO 1055 CR extract (group CR) respectively in the test groups; $C$ presents the control group. Values are expressed as the mean $\pm S D\left({ }^{*} p<0.05\right.$ vs $C,{ }^{\Delta} p<0.05$ vs $\left.E\right)$.

Tab. 2: Quantitative evaluation of the three central microradiographic sections to examine tibial callus formation after treatment with Black cohosh extract BNO 1055 $(\mathrm{CR})$ and $17-\beta$ estradiol $(\mathrm{E})$ in severe osteoporotic rats. Values are expressed as the mean \pm SD. $\left({ }^{*} p<0.05\right.$ vs $C,{ }^{\Delta} p<0.05$ vs $\left.E\right)$.

Fig. 1: The three arms of the study with the specific diets and their nutrient composition. 36 ovariectomized rats received phytoestrogen-free rodent chow for 10 weeks while developing osteopenia. After metaphyseal tibia osteotomy they were divided in 3 groups containing 12 rats each, receiving pure phytoestrogen-free chow (C), 17-B-estradiol supplemented chow (E) or cimicifuga racemosa (BNO 1055) supplemented chow $(\mathrm{CR})$ during the fracture healing period of $35 \mathrm{~d}$.

Fig. 2: I. Examplary microradiography with the scheme of the determined parameters of the callus formation [callus density ventromedial/endosteal/dorsal (CI.Dn.v/e/d), callus width (Cl.Wi. v/e/d)] as well as the cortical situation [cortical density and width ventromedial/dorsal (Ct.Dn/Wi v/d)] and trabecular structure [trabecular density and width (Tr.Dn/Wi), number of trabecular nodes (N.Nd)]. II. Example of Quantimet ${ }^{\circledR}-$ based evaluation of fluorescence-labeled sections: a native picture, $\mathbf{b}$ cortical structure colored, c CG-labeled callus [fluorochrome labeling with calcein green (CG: day 18)], d AK-labeled callus [fluorochrome labeling with alizarin red (AK: day 24 and 26)], e TC-labeled callus [fluorochrome labeling with tetracycline (TC: day 35)], f entire callus area.

Fig. 3: Stiffness and yield load (sole and BW-related) of the metaphyseal tibiae from the bending test. a and $\mathbf{c}$ : the stiffness $(\mathrm{S})$ and yield load $(\mathrm{yL})$ were highest in the $\mathrm{E}$ substituted group (E), followed by the CR group (CR), being slightly improved in 
comparison to osteopenic C. $\mathbf{b}$ and $\mathbf{d}$ : $\mathrm{S}$ and $\mathrm{yL}$ showed the same distribution when related to body weight, but differences were more apparent. Especially in the E group $y L$ was significantly enhanced vs. C. Values are expressed as the mean $\pm S D\left({ }^{*} p<\right.$ 0.05 vs $\mathrm{C})$.

Fig. 4: Quantitative evaluation of microradiographic sections of tibiae under 17-Bestradiol- (E) and cimicifuga racemosa (CR) supplementation vs. osteopenic control group C. Exemplarily shown: a Callus width dorsal (CI.Wi.d), b callus density endosteal (Cl.Dn.e), $\mathbf{c}$ trabecular width (Tr.Wi) and $\mathbf{d}$ number of trabecular nodes (N.Nd). Values are expressed as the mean $\pm S D\left({ }^{*} p<0.05\right.$ vs $\left.C\right)$.

Fig. 5: Corresponding microradiographic and fluorescence-labeled sections. Estrogen (E) induced a very dense and compact callus, and maximally increased the trabecular structure compared to the osteopenic $\mathrm{C}$ group. Under CR (Cimicifuga racemosa)-donation the callus structure was slightly enhanced as compared to $\mathrm{C}$, but levels did not reach those of the E group.

Fig. 6: Quantitative analysis of bone healing at the metaphyseal tibia after intravital fluorochrome labeling with calcein green (CG: day 18), alizarin red (AK: day 24 and 26) and tetracycline (TC: day 35 ) at the a ventromedial, $\mathbf{b}$ dorsal and $\mathbf{c}$ endosteal region. One-way ANOVA and Tukey-Kramer post-hoc test (PrismTM, GraphPad, San Diego, USA). $\mathbf{d}$ Average total callus area after 35 days of fracture healing. Values are expressed as the mean $\pm \mathrm{SD} .{ }^{*}=p<0.05$ vs. CG-area of same group, $\Delta=p<0.05$ vs. AK-area of same group). 
Table 1: Changes in bodyweight determined at ovariectomy, osteotomy and obduction. Daily food intake and daily intake of pure $17 \beta$ estradiol (group E), or BNO 1055 CR extract (group $\mathrm{CR}$ ) respectively in the test groups; $C$ presents the control group. Values are expressed as the mean $\pm S D\left({ }^{*} p<0.05\right.$ vs $C,{ }^{\Delta} p<0.05$ vs $\left.E\right)$.

$\begin{array}{lll}\text { C } & \text { E } & \text { CR } \\ \text { Mean } \pm S D & \text { Mean } \pm S D & \text { Mean } \pm S D\end{array}$

\section{Body Weight [g]}

Ovariectomy

Osteotomy

Obduction

Food intake after osteotomy [g/d/rat]
$228.8 \pm 14.04$

$347.6 \pm 19.97$

$342.2 \pm 19.91$

$17.19 \pm 2.89$
$238.0 \pm 12.53$

$347.8 \pm 16.06$

$280.3 \pm 12.05^{*}$

$235.9 \pm 11.83$

$332.5 \pm 26.18$

$317.3 \pm 23.31^{\Delta}$

$11.57 \pm 0.11$

$15.01 \pm 0.89$

$0.097 \pm 0.002$ 
Table 2 Quantitative evaluation of the three central microradiographic sections of the tibia callus formation after therapeutically treatment with Black cohosh extract BNO 1055 (CR) and 17- $\beta$ estradiol $(E)$ in severe osteoporotic rats (average value \pm SD of the mean)

\begin{tabular}{l|lll} 
& C & CR & E \\
& Mean \pm SD & Mean \pm SD & Mean \pm SD \\
\hline Cortical width ventro-medial (Ct.Wi.v) [mm] & $0.35 \pm 0.08$ & $0.34 \pm 0.06$ & $0.34 \pm 0.04$ \\
Cortical width dorsal (Ct.Wi.d) [mm] & $0.49 \pm 0.1$ & $0.45 \pm 0.11$ & $0.44 \pm 0.12$ \\
& & & \\
Cortical density ventro-medial (Ct.Dn.vm)[\%] & $98.38 \pm 1.52$ & $99.04 \pm 1.68$ & $98.88 \pm 1.11$ \\
Cortical density dorsal (Ct.Dn.d) [\%] & $99.11 \pm 0.94$ & $99.14 \pm 0.89$ & $99.59 \pm 0.34$ \\
& & & \\
Callus width ventro-medial (Cl.Wi.vm) [mm] & $0.35 \pm 0.2$ & $0.22 \pm 0.12$ & $0.23 \pm 0.16$ \\
Callus width dorsal (Cl.Wi.d) [mm] & $0.72 \pm 0.51$ & $0.49 \pm 0.27$ & $0.49 \pm 0.2$ \\
& & & \\
Callus density ventro-medial (Cl.Dn.v) [\%] & $59.36 \pm 16.24$ & $56.11 \pm 17.72$ & $54.86 \pm 23.62$ \\
Callus density dorsal (Cl.Dn.d) [\%] & $67.59 \pm 14.84$ & $67.16 \pm 17.63$ & $67.61 \pm 15.02$ \\
& $11.47 \pm 9.81$ & $10.93 \pm 8.49$ & $14.68 \pm 8.62$ \\
Trabecular density (Tr.Dn) [\%] & $7.12 \pm 11.65$ & $6.87 \pm 13.67$ & $10.19 \pm 11.93$ \\
Nodular density (Nd.Dn) [\%] & & &
\end{tabular}




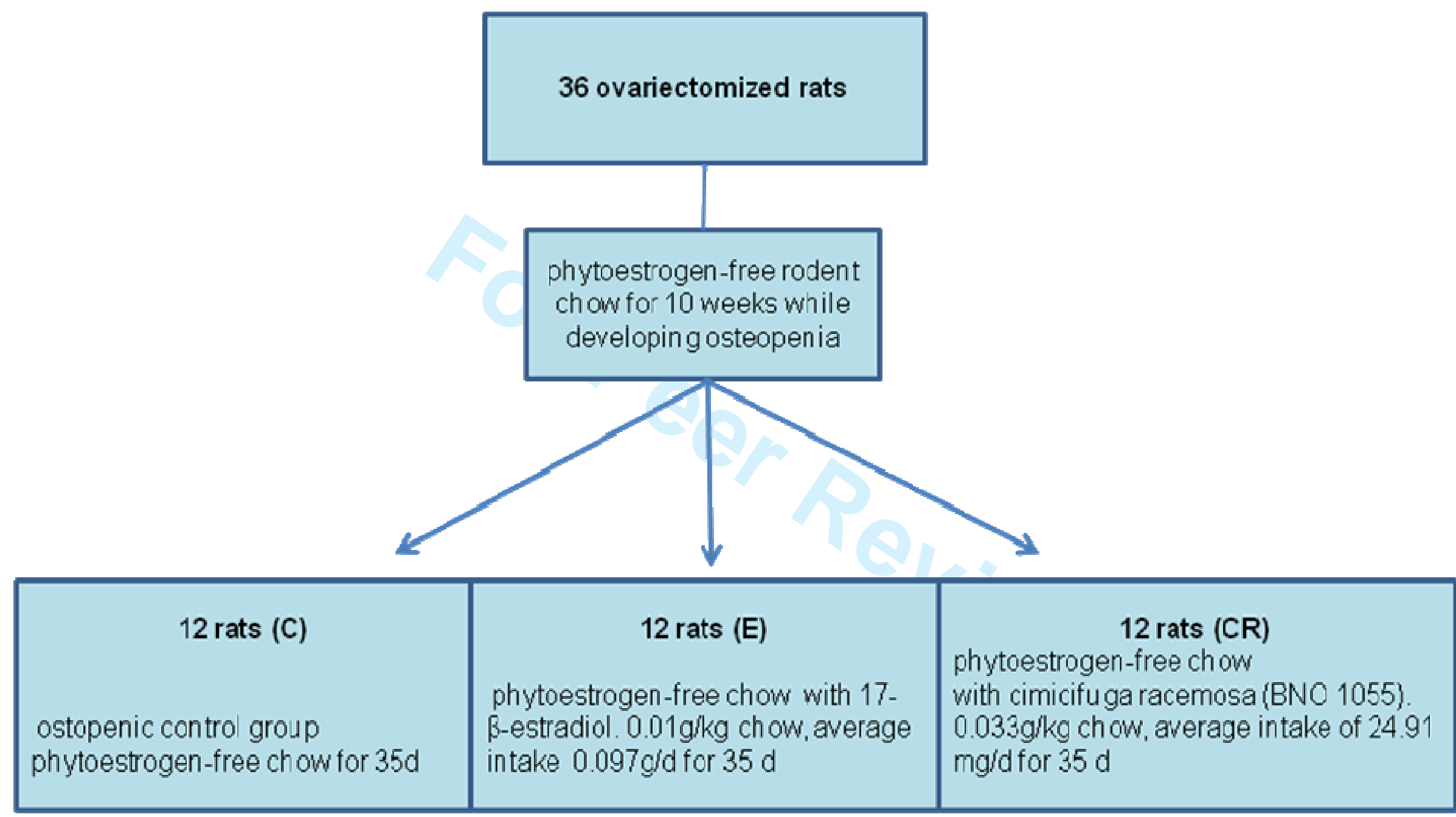

\section{Figure 1}




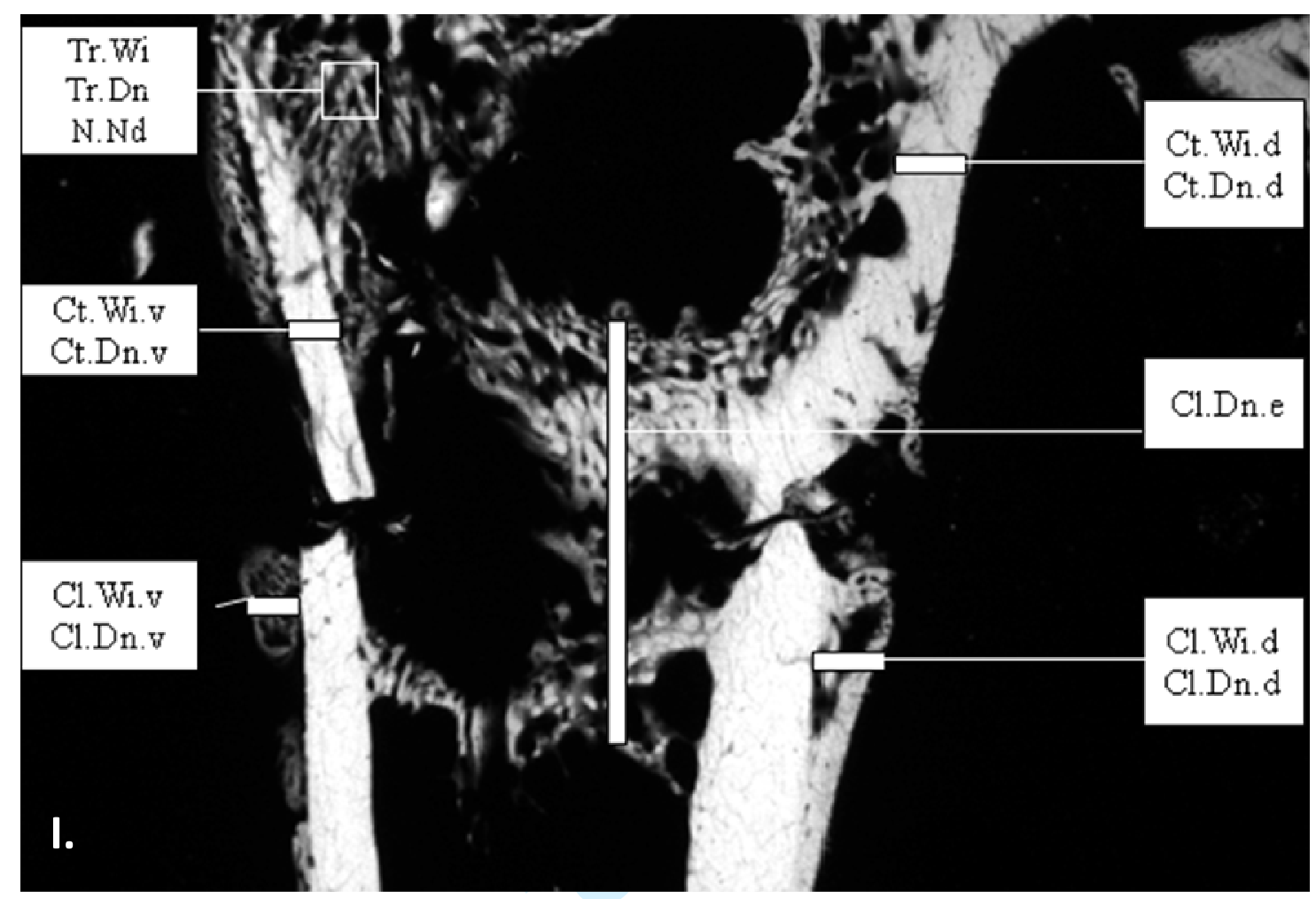



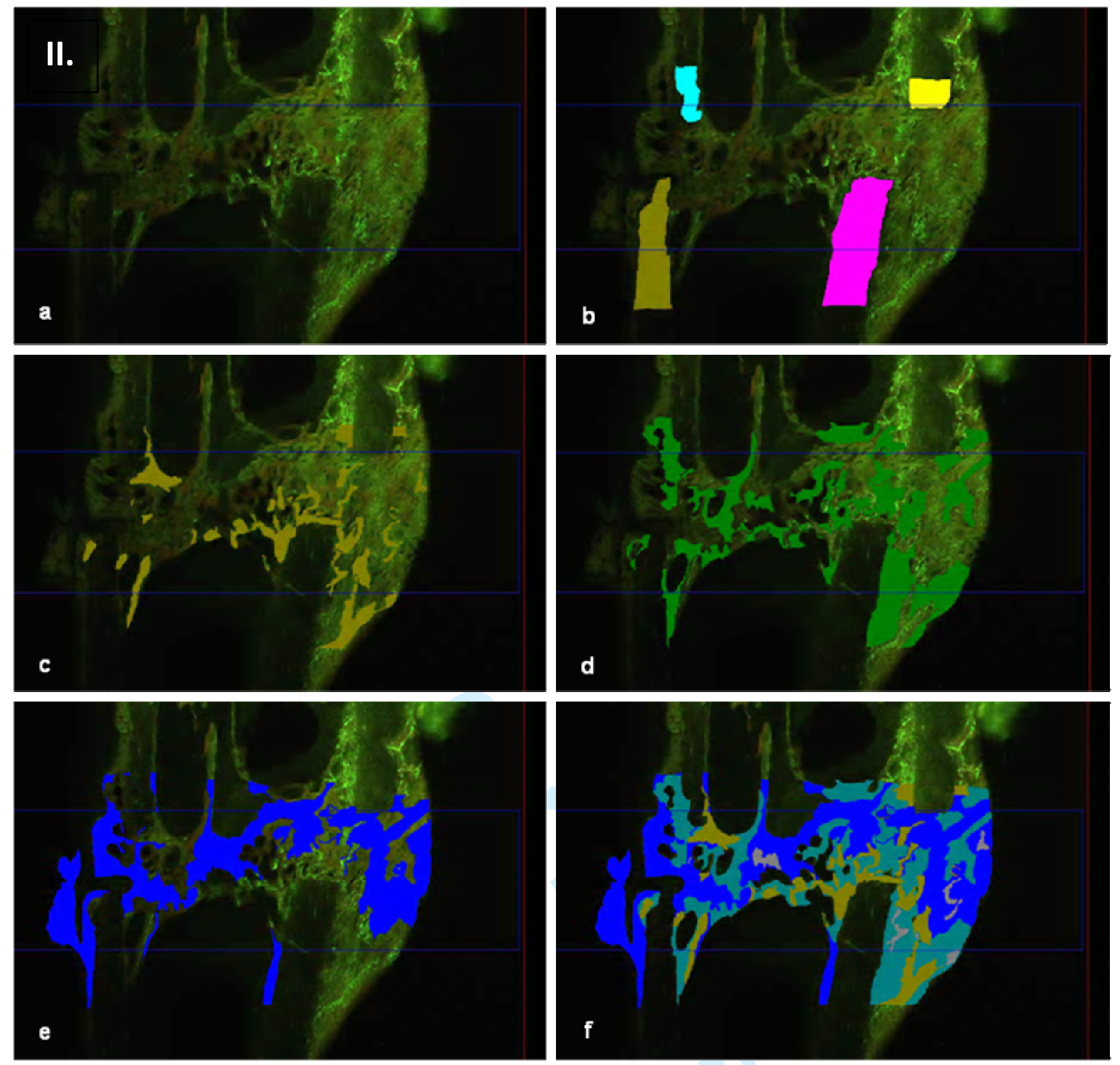

Figure 2 

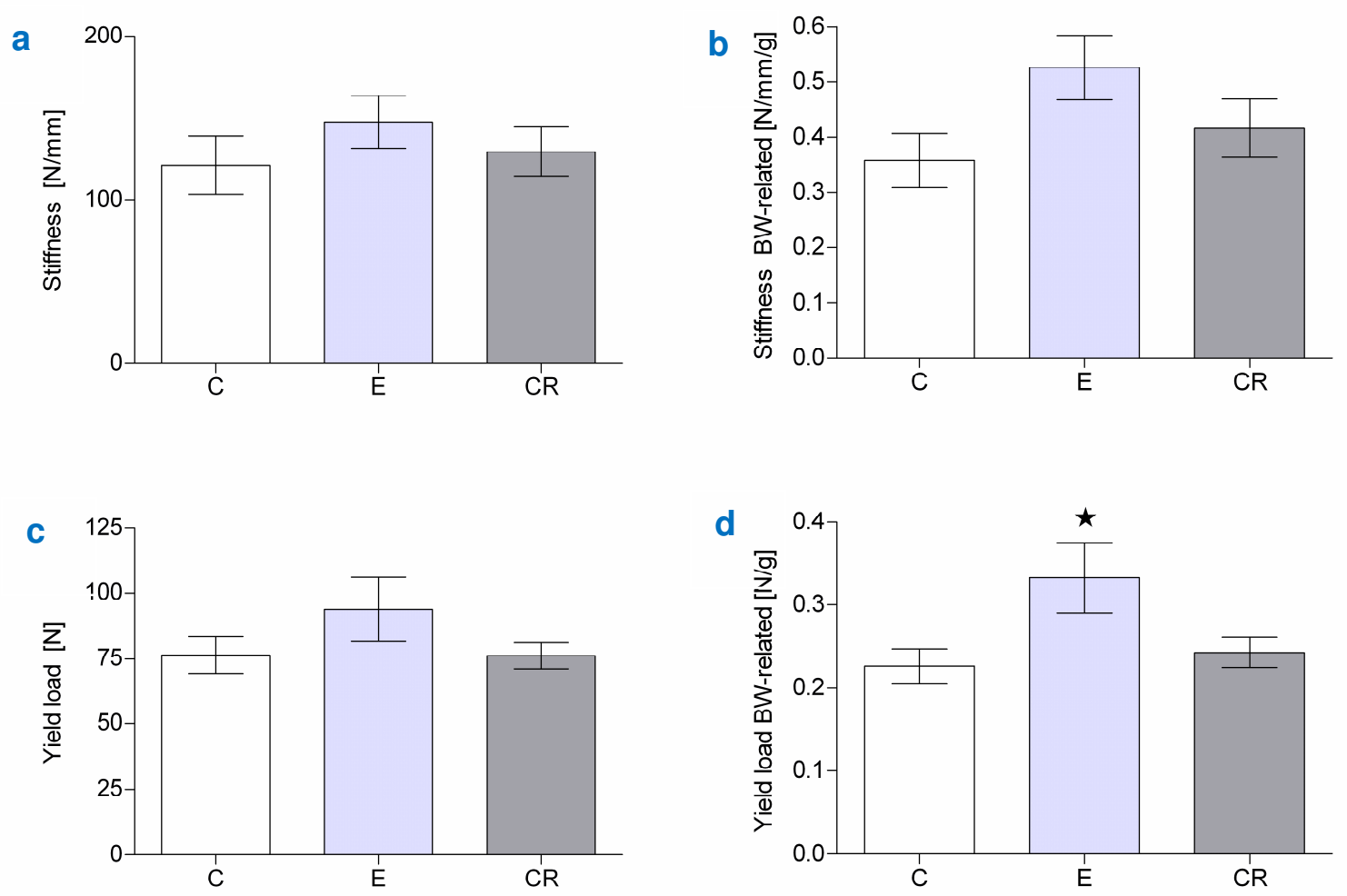

Figure 3 

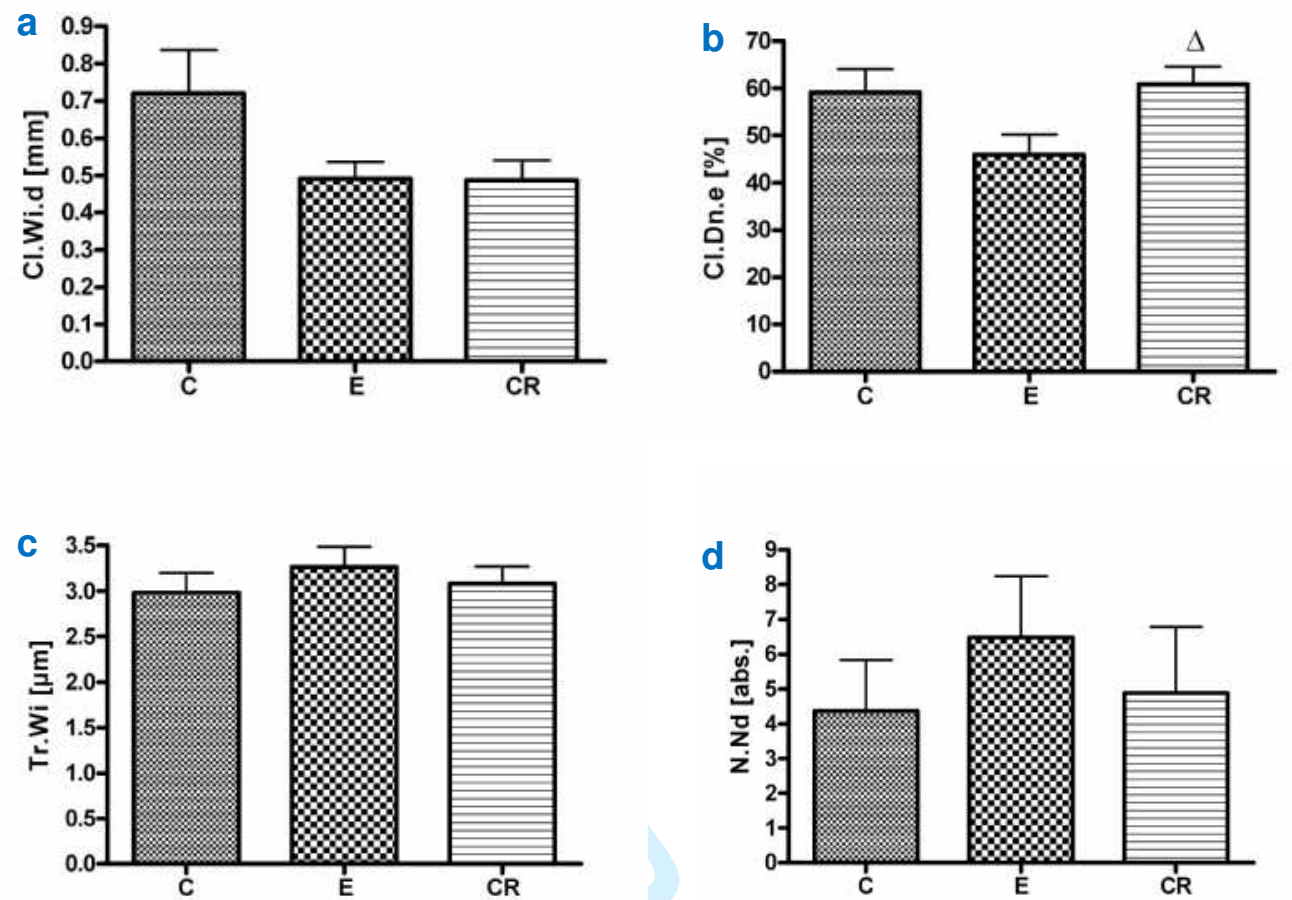

\section{Figure 4}



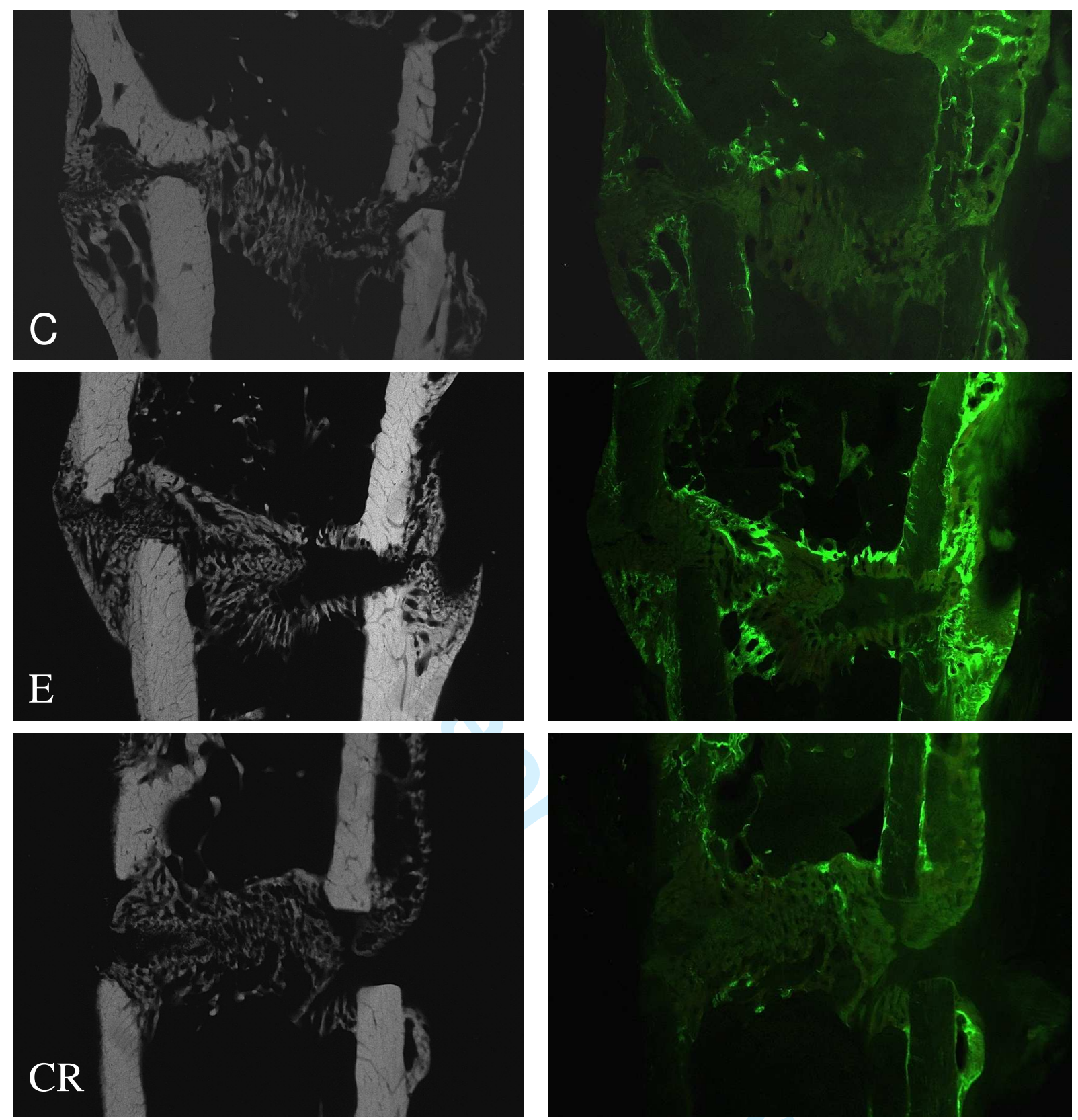

Figure 5 
a
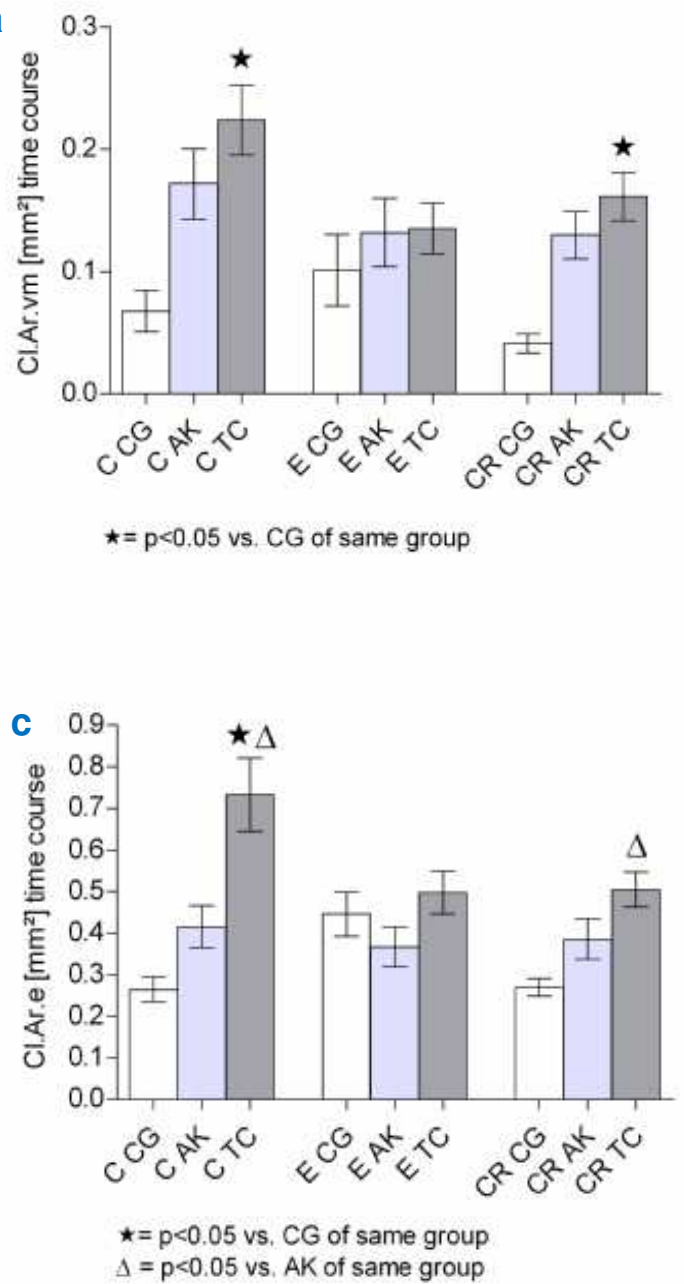

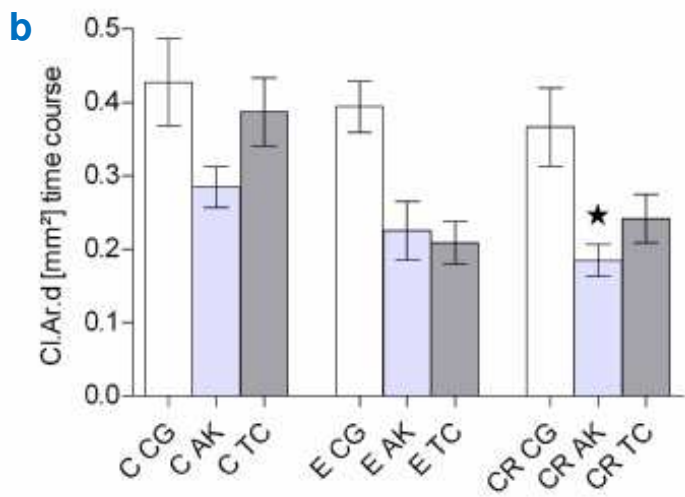

$\star=p<0.05$ vs. CG of same group

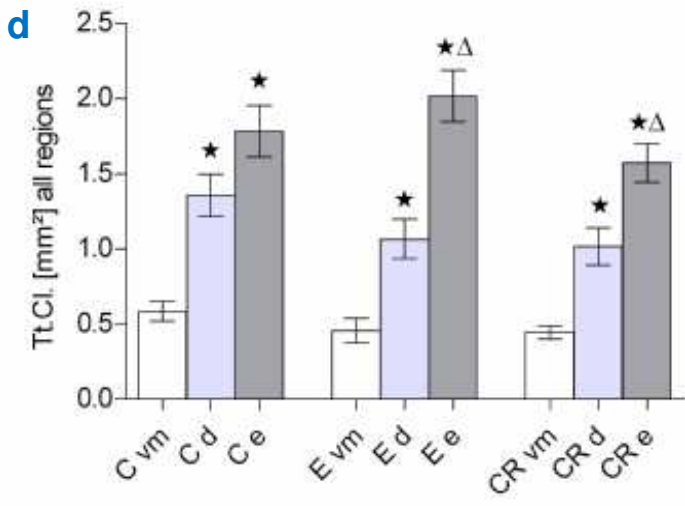

$\star=p<0.05$ vs. vm area of same group $\Delta=p<0.05$ vs. $d$ area of same group

Figure $6(a, b, c, d)$ 